\title{
Non Hodgkin's Lymphoma of Ileum and Cecum presented as Pelvic Abscess followed by Right Iliac Fossa mass- a rare presentation.
}

\author{
Jagdish B ${ }^{\mathrm{a}}$, Shekar Y Tati ${ }^{\mathrm{a}}$, GopinathPai ${ }^{\mathrm{a}}$, GanapathyPuranik ${ }^{\mathrm{a}}$, SomdeepGhosh $^{\mathrm{b}}$, \\ Harris Mohammed $\mathrm{P}^{\mathrm{b}}$, Karthikeyan $\mathrm{K}^{\mathrm{b}}$, AkshayPai ${ }^{\mathrm{b}}$, Navya $_{\mathrm{BN}}{ }^{\mathrm{c}}$ \\ ${ }^{a}$, Professor, ${ }^{b}$, Post graduate, department of general surgery. c,Assistant professor, department of \\ pathology.KVG Medical College \& Hospital, Sullia-DK, Karnataka, India.
}

\begin{abstract}
Gastro intestinal tract is most common primary site of extra nodal non Hodgkin's lymphoma. Stomach is the common site in the GI tractfollowed by ileum, jejunum and duodenum. Colon is very rarely involved. Histologically it is B or T cell type with small or large cell variation.

Diagnosis is difficult since lymphoma presents with vague abdominal pain with loss of weight and loss of appetite. It may present as lump abdomen with complications such as intestinal obstruction, bleeding, perforation and peritonitis. Perforation is the least common presentation.

In our case a 48 year old male presented with pain abdomen followed by vomiting and distension of abdomen. A diffuse soft mass was occupying the umbilical region, right iliac and pelvic fossae. USG abdomen and CT scan showed large pelvic and peritoneal collections. Pelvic abscess responded to conservative treatment. Two weeks later patient developed right ileac fossa mass which was hard inconsistency. On exploratorylaporotomy mass was found in the ileo-cecal region. Right hemicolectomy was done. Histologically the specimen was reported as NHL of terminal ileum and cecum.

We wish to present this case because, growth synchronously presenting in the ileum and cecum israre. NHL Lymphoma arising from two sites was reported in theileum but lymphoma arising fromboth ileum and cecum was probably not reported.
\end{abstract}

Key words: CT scan abdomen (Computerised Tomographic Scan), GI tract - gastro intestinal tract ,Non Hodgkin's Lymphoma-NHL, USG abdomen (ultra sonogram).

\section{Introduction}

Non Hodgkin's lymphoma is mostly lymph nodal disease however it can arise from organs like GItract, thyroid, testis and ovary. GI tract is most common primary site of extra nodal non Hodgkin's lymphoma. Stomach $(50-60 \%)$ is the most common site in the GI tract followed by small bowel $20-30 \%$ and very rarely colon[1]. In the colon cecum is the most common site and it is mainly due to spread from ileum.Ileum is the most common site for primary lymphoma followed by jejunum and duodenum [2-6].GI tract lymphoma is more common in males, male to female ratio is 2:1[1]. The incidence of GI tract lymphoma ismore inimmune compromised patients [1]. Clinical diagnosis of GI tract lymphoma is very difficult since patient presentswith vague symptoms likeabdominal pain, loss of weight and loss of appetite. Diagnosis can only be made post operatively whenpatient is operated for complications such as intestinal obstruction, haemorrhage and perforation.

If patient presents with a mass, it can be evaluated by USG guided cytology, or CT guided biopsy. On histological examination NH Lymphoma can be small or large cell variety of B cell or T cell type lymphocytes. B cell lymphoma is more common than T cell lymphoma. Prognosis is better in B cell type as compared T cell lymphoma. And large cell lymphomas are associated with poor prognosis.

Surgical treatment is mandate once patient presents with complications otherwise non surgicaltreatment is the option. Surgical resection is most common method in a mass lesion followed by adjuvant chemoradiation. However recurrence rate is high after chemoradiation in GI tract lymphomas [7].

\section{Case Report}

48 year old male presented with pain and distension of abdomen for seven days. Patient had intermittent low grade fever. Patient was a chronic smoker and takes alcohol occasionally. There is h/o loss of appetite but no weight loss.

On examination moderate abdominal distension was present with mild tenderness in the right lower abdomen. Vague mass was felt in the right lower abdomen with diffuse borders. Noorganomegalyorfree fluid was present in the peritoneal cavity. Per rectal examination revealed soft boggy swelling in the rectovesical pouch. Pelvic abscess was ourprovisional diagnosis. 
USG abdomen showed large multi loculated cystic lesion in the right hemi pelvis extending in to right ileac fossa. CT abdomen showed diffuse wall thickening of terminal ileum with locoregional lymphadenopathy. Multiple loculated mesenteric collections with air fluid levels were noted, largest collection measuring 500ccwas located in the recto-vesical pouch (fig. 1). CT impression was inflammatory bowel disease with loculatedpelvic and mesenteric collection.

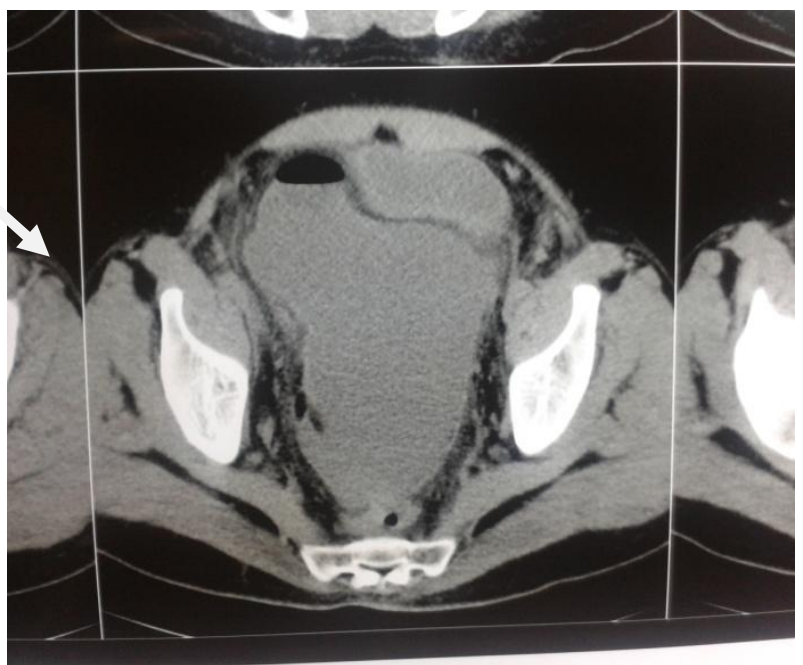

Figure 1 CT showing large pelvic abscess

Diagnosis was confirmed by aspirating $10 \mathrm{ml}$ of frank pus per rectally and sent for culture sensitivity.Culture yieldedklebsiella, sensitive to amino glycosides. Pelvic collection completely resolved within two weeks of antibiotic treatment. Patient was discharged. Probably lymphoma cecum was obstructing the appendix which got perforated leading to peritonitis and pelvic abscess. Perforation of the gut is one form of complication of lymphoma.

Two weeks later patient came with right ileac fossa masswhich was rapidly increasing in size. Exploratory laporotomy was done. On exploration a single mass was present involving thecaecum, loops of terminal ileum, ascending colon and greater omentum.Mesenteric lymphnodes were enlarged.Right hemicolectomy was done(fig.2) with ileo-transverse colonic anastomosis. Patient recovered uneventfully.

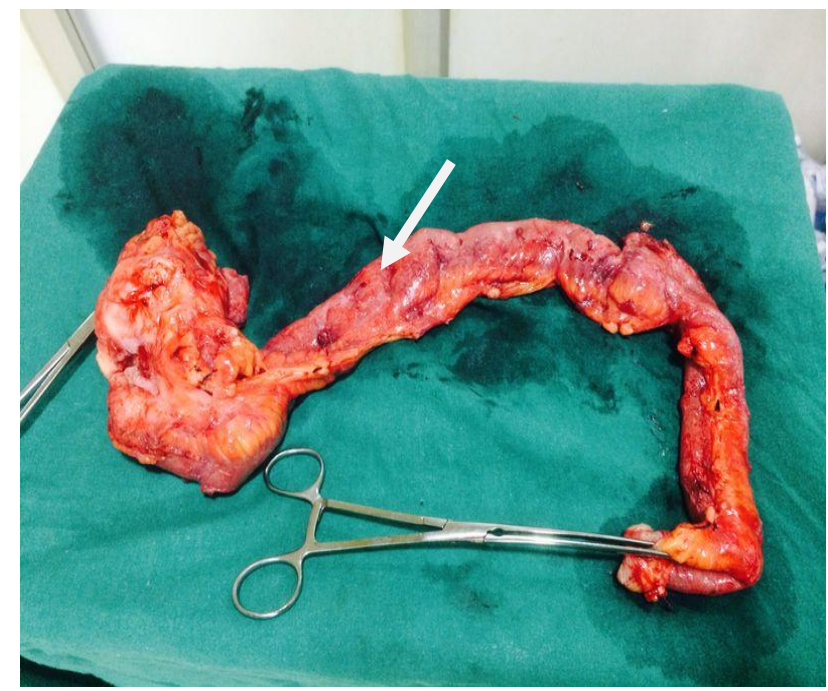

Figure 2 Right hemicolectomyspecimen( Arrow showing growth in the cecum and another growth in terminal ileum)

Gross specimen consists of terminal ileum and caecum measuring about $53 \mathrm{~cm}$ long (fig.3).Cut section showed diffuse infiltrative gray white fleshy masses one located in the cecum measuring $15 \times 8 \times 7 \mathrm{~cm}$ extending to ascending colon. Another mass was located in the terminal ileum measuring $3 X 3 \mathrm{~cm}$. 


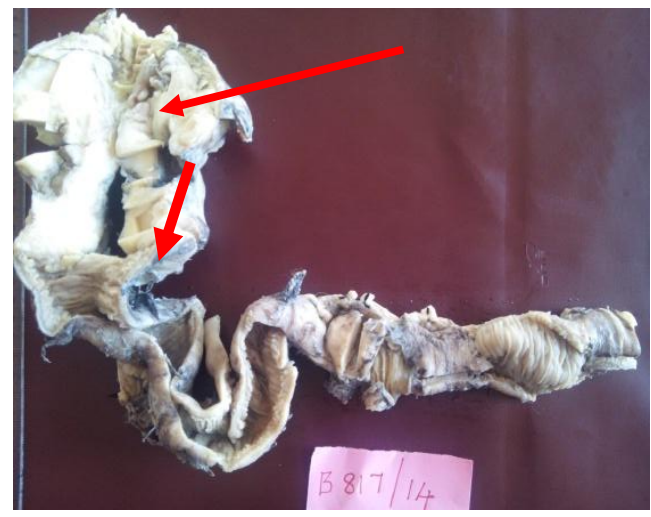

Figure 3 Gross specimen showing cecal and ileal growth with wall thickening.

Microscopic examination (fig.4) revealed diffuse monotonous population of abnormallymphoidal cells were seen infiltrating muscular layer extending on to serosa. The individual cells are large cleaved having abundant eosinophilic cytoplasms and round to oval nuclei few showing prominent nucleoli. Increased mitotic figures were evident. Impression: Non Hodgkin's lymphoma of GI tract involving cecum and terminal ileium.

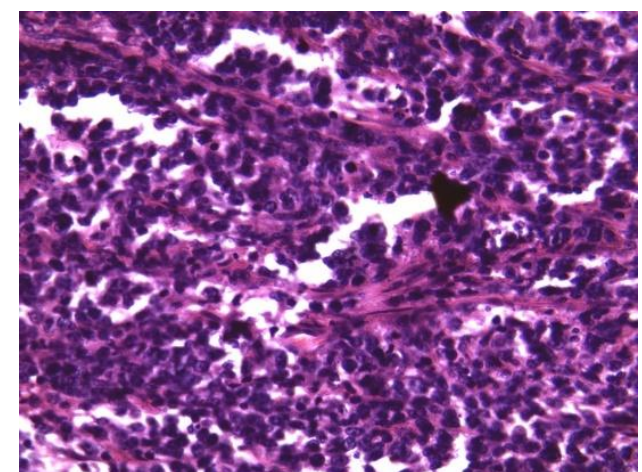

Figure 4- Microscopy showing abnormal lymphoidal cells infiltrating muscularis extending up to serosa

After two weeks patient again developed mass in the same area which was rapidly increasing in size. USG abdomen was showing nodal mass.Patient was referred for further management.

\section{Discussion}

GIT is the most common site for extra nodal Non Hodgkin's primary lymphoma[1, 8-9]. The most common site is being stomach (50-60\%), small bowel (20-30\%) and rarely colon. In the small bowel ileum $(58 \%)$ is the most common site followed by jejunum(26.5\%) and duodenum (17.6\%) since gut associated lymphoid tissue is more common in ileum. It has been reported that $20 \%$ of small bowel lesions are primary lymphomas of non Hodgkin's type [1].It is a very rare tumour but common malignanttumour of the small bowel after adenocarcinoma. On intense search of literature one case of lymphoma arising from cecum was reported[7]. Synchronous growths both in the ileum and cecum wereprobably not reported in the literature. However synchronous growths of lymphoma arising from two sites in the ileum werereported [1].

Small bowel lymphomas are rare [10]. The incidences are increasing in recent years particularly in immune compromised patients [11-13]. The reported incidences of small bowel lymphoma are more in the east than the western world [2-6]. It is more common in males than females: male female incidence is 2:1[1].

Etiopathogenisis of small bowel lymphoma is not clearly known but research suggests that small bowel lymphoma originates from local antigen-responsive B cells.Because of this reason $70 \%$ of the neoplasms are B cell lymphoma of large cell variety. Incidentally our case was also reported aslargecell Bcell type lymphoma.However known risk factors likeceliac disease, immune suppression after organ transplant, retroviral infection (HIV) and inflammatory boweldisease have been identified[14-17].

Patient canpresent with pain abdomen in $70 \%$ of the cases along with loss of appetite and loss of weight. Patient sometimes present with complications such as intestinal obstruction 38\%, bleeding and perforation [18].Our case also presented with complication of perforation resulted in large pelvic abscess with peritoneal collections. The findings mentioned above are all nonspecific and did not lead us to clinical diagnosis. 
It is difficult to screen the small bowel however CT with contrast may help in suspected case of small bowel lymphoma. Otherwise it is a post operative diagnosis.

Treatment strategy is not clear in small bowel lymphoma. Surgery is being attempted in lymphoma with complications. Diagnosis is confirmed withhistopathological specimen. Reports are available that complete surgical excision in early stage prolongsthe disease free survival rate [19-22]. Various trials have been shown surgery combined with chemotherapy had improved the survival rate [1].

However one study shows the recurrence rate after surgery with radiotherapy was $8.3 \%$, chemoradiationwas $13.3 \%$ and chemotherapy alone was $25 \%$ where radiotherapy associates with least recurrent disease [7].No unified reports are available for chemo and radio therapy. Over all GI tract lymphomas responds poorly than nodal NHL lymphoma. Anti CD20- monoclonal antibodies have shown to be effective against CD20-positive low grade follicular lymphoma. Rituximab is the optimal treatment for primary small bowel lymphoma [1].

\section{Conclusion}

Most common site for primary non Hodgkin's lymphoma in GI tract is stomach followed by ileum, jejunum and duodenum.Diagnosis is delayed so also treatment since patient presents with non specific symptoms like pain abdomen, loss of weight and loss of appetite. Patient may present with complications like obstruction,hemorrhage and perforation which compels the surgeon to operate. Histologically two types are identified,B cell and T cell lymphoma of large cell and small cell variety. B cell lymphoma is more common in small bowel and is associated with good prognosis when compared to T cell lymphoma. Radical surgery improved the survival rate, radical surgery with chemotherapy further improved survival rate. However no clear reports are available regarding chemo radiation treatment of GIT lymphoma.

\section{Reference}

[1]. L YIN, CQ CHEN, CH PENG, GM CHEN, HJ ZHOU, BS HAN AND HW LI. Primary Small-bowel Non-Hodgkin's Lymphoma: a Study of Clinical Features, Pathology, Management and Prognosis, The Journal of International Medical Research 2007; $35: 406$ 415 .

[2]. Dincol D, Icli F, Erekul S, et al: Primary gastrointestinal lymphomas in Turkey: a retrospective analy sis of clinical features and results of treatment. J SurgOncol 1992; 51: $270-273$

[3]. Otter R, Bieger R, Kluin PM, et al: Primary gastrointestinal non-Hodgkin's lymphoma in a population-based registry. Br J Cancer 1989; 60: $745-750$

[4]. Salem P, Anaissie E, Allam C, et al: Non- Hodgkin's lymphomas in the Middle East. A study of 417 patients with emphasis on special features. Cancer 1986; 58: 1162 - 1166

[5]. Koch P, del Valle F, Berdel WE, et al: Primary gastrointestinal non-Hodgkin's lymphoma: I. Anatomic and histologic distribution, clinical features, and survival data of 371 patients registered in the German Multicentric Study GIT NHL 01/92. J ClinOncol 2001; 19: $3861-3873$

[6]. Amer MH, El-Akkad S: Gastrointestinal lymphoma in adults: clinical features and management of 300 cases. Gastroenterology 1994; 106: 846 - 858 .

[7]. Chul S. Ha, Moon-June Cho, Pamela K. Allen, Lillian M. Fuller, Fernando Cabanillas, James D. Cox. Primary Non-Hodgkin Lymphoma of the Small Bowel. Radiology 1999; 211:183-187.

[8]. Howdle PD, Jalal PK, Holmes GKT, et al: Primary small-bowel malignancy in the UK and its association with coeliac disease. Q J Med 2003; $96: 345-353$.

[9]. Lee J, Kim WS, Kim K, et al: Intestinal lymphoma: exploration of the prognostic factors and the optimal treatment. Leuk Lymphoma 2004; 45: $339-344$.

[10]. Ahmed S, Singh A, Krauss J, et al: Successful treat- ment of refractory low grade duodenalL Yin, CQ Chen, CH Peng et al. Retrospective study of primary small-bowel non-Hodgkin's lymphoma lymphoma with rituximab, an anti-CD20 monoclonal antibody. Am J ClinOncol 2003; 26: 408 - 410.

[11]. Nalesnik MA, Jaffe R, Starzl TE: The pathology of post-transplant lymphoproliferative dis- orders occurring in the setting of cyclosporin A-prednisone immunosuppression. Am J Pathol 1988; 133: 173 - 192.

[12]. Levine AM: Acquired immunodeficiency syndrome-related lymphoma. Blood 1992; 80: $8-20$.

[13]. Bende RJ, Smit LA, Bossenbroek JG, et al: Primary follicular lymphoma of the small intestine: alpha4beta7 expression and immunoglobulin configuration suggest an origin from local antigen-experienced B cells. Am J Pathol 2003; $162: 105-113$.

[14]. Foss HD, Stein H: Pathology of intestinal lymphomas. Recent results. Cancer Res 2000; 156: $33-41$.

[15]. Berney T, Delis S, Kato T, et al: Successful treatment of posttransplantlymphoproliferative disease with prolonged rituximab treatment in intestinal transplant recipients. Transplantation 2002; 74: $1000-1006$.

[16]. Hall CH Jr, Shamma M: Primary intestinal lymphoma complicating Crohn's disease. J ClinGastroenterol 2003; 36 : 332 - 336.

[17]. Huang Q, Chang KL, Gaal K, et al: Primary effusion lymphoma with subsequent development of a small bowel mass in an HIVseropositive patient: a case report and literature review. Am J SurgPathol 2002; 26:1363 - 1367.

[18]. Chim CS, Loong F, Leung AY, et al: Primary follicular lymphoma of the small intestine. Leuk Lymphoma $2004 ; 45: 1463$ - 1466.

[19]. Ibrahim EM, Ezzat AA, Ei-Weshi AN, et al: Primary intestinal diffuse large B-cell non- Hodgkin's lymphoma: clinical features, management, and prognosis of 66 patients. Ann Oncol 2001; 12: $53-58$.

[20]. Rackner VL, Thirlby RC, Ryan JA Jr: Role of surgery in multimodality therapy for gastrointestinal lymphoma. Am J Surg 1991; 161: $570-575$.

[21]. Radman I, Kovacevic-Metelko J, Aurer I, et al: Surgical resection in the treatment of primary gastrointestinal non-Hodgkin's lymphoma: retrospective study. Croat Med J 2002; 43: 555 - 560.

[22]. Bobbi PG, Ghirardelli ML, Cavalli C, et al: The role of surgery in the treatment of gastrointestinal lymphomas other than lowgrade MALT lymphomas. Haematologica 2000; 85: $372-380$. 